\title{
De nuevo Estrabón III, 4, 6-8
}

\author{
Carmen ARANEGUI GASCÓ, \\ Universitat de València.
}

\section{Resumen}

¿Por qué hay tantas monedas y joyas antiguas ocultas en el Montgó? ¿Por qué se edificó (y se destruyó) la fortaleza de La Picola? ¿Por qué se escribió la lengua ibérica con signos jonios en el sureste? Este trabajo propone relacionar estos hechos con la cita de Estrabón III, 4, 6 y establecer en el siglo IV a.C. la fecha del contacto de la zona implicada con Massalia.

Palabras clave: Colonización focea. Iberia. Massalia. Hemeroskopeion.

\section{Summary}

Why are there so many ancient coins and jewels hidden in the Montgó? Why was La Picola fortress built (and destroyed)? Why was Iberian language written with lonic signs in the South-East of Spain? This paper tries to relate these events to the passage of Strabo III, 4, 6, and to establish the date of the 4th century B.C. as the moment when Massalia was contacted.

Keywords: Phocaian colonization. Iberia. Massalia. Hemeroskopeion.

\section{INTRODUCCIÓN}

Entre el Sucro y Carthago hay tres pequeñas ciudades de los masaliotas, no muy lejos del río. De ellas la más importante es Hemeroskopeion, que tiene en su peñón un templo de la Artemis muy célebre...

Str. III, 4, 6 (versión castellana de A. Schulten, $F H A$ )

Con ocasión del homenaje de la Universidad Autónoma de Madrid a Manuel Bendala Galán me complace retomar el tema del factor helénico en las culturas de Iberia, recurrente en algunos de nuestros respectivos trabajos, que tienen en común el haber sido recibidos con cierta indiferencia por la investigación. Desde la época de sus primeros estudios sobre la necrópolis de Carmo (1976) hasta la etapa reciente dedicada a Carteia
(Roldán et al., 2006), el profesor Bendala ha insistido con acierto en la importancia de la huella helenística introducida en la arquitectura prerromana por el proyecto político de los Barka (Bendala, 2001: 37-52; Bendala, Blánquez, 20022003: 145-159). Y yo, por mi parte, he permanecido atenta a los flujos comerciales griegos occidentales en las costas mediterráneas ibéricas, desde la época de mis estudios sobre las jarritas grises ampuritanas. El eco de ambas propuestas ha sido, repito, relativamente discreto. Pero la perseverancia en un tema facilita que, con el paso del tiempo, se pueda ofrecer una perspectiva progresivamente ampliada, como me dispongo a hacer en referencia a la influencia griega sobre el litoral mediterráneo suroriental en el Ibérico Pleno, situándome más allá de la distribución de ánforas y cerámicas. 
Mi punto de partida consiste en admitir y probar la política expansiva de Massalia (Str. IV, 1, 9) hacia Iberia, tal y como reflejan las fuentes clásicas (Str. III, 4, 6-10; OM 470-471; St. Byz. s.v.) y, pese a los escépticos, confirman la historia (Ebel, 1976:20) y la arqueología, relacionando una serie de hechos centrados en el siglo IV a.C.

Descartada la presunta antigüedad de Rhode y su fundación por los rodios (Maluquer de Motes, 1965: 17-22; Rouillard, 1991:330, n.378), el reciente estudio de las excavaciones de Rosas (Puig, Martín, 2006; Puig, 2010: 79-88), de su barrio artesanal y de sus producciones cerámicas, resulta muy oportuno para apoyar la tesis que aquí se va a exponer, porque despeja, por una parte, la cronología de la apoikía (375 a 195 a.C.), por otra, su vinculación a Marsella y, finalmente, su relación con el medio indikete $\mathrm{y}$, en particular, con el oppidum de Peralada, que se abandona hacia el 300 a.C. (Llinàs et al., 1998), todo lo cual establece una secuencia histórica que afecta a la colonización y a la población local, extrapolable, con las necesarias modificaciones, a otras áreas situadas más al sur.
Si se contempla un contexto cronológico similar al de Rosas para los pequeños establecimientos del entorno del cabo de la Nao que Estrabón relaciona con Marsella -Hemeroskopeion y las pequeñas localidades al sur del Júcar- se hace posible integrarlos en el mismo proyecto que la metrópolis focalizó en Rhode, así como entenderlos como resultado del intento foceo-masalieta de sentar plaza en el sureste peninsular para explotar sus recursos, con participación de la población local. La distribución de las ánforas masalietas, seguida por la cerámica de pequeñas estampillas (Pérez Ballester, 1994: 189-205) y del barniz negro de Rosas, bien atestiguados desde El Grau Vell (Sagunto) (Aranegui, 2004: 80) (fig. 1) hasta El Cigarralejo (Mula) (García Cano, 2005: 84), además de las cerámicas grises del norte de Cataluña y de las ánforas y morteros masalietas, jalonan esta proyección durante el periodo en que estuvo vigente Rosas, porque la distribución de bienes tiene su propia dinámica, de modo que intentaré contrastarla añadiendo otros hechos esclarecedores que someto a la consideración de los lectores.
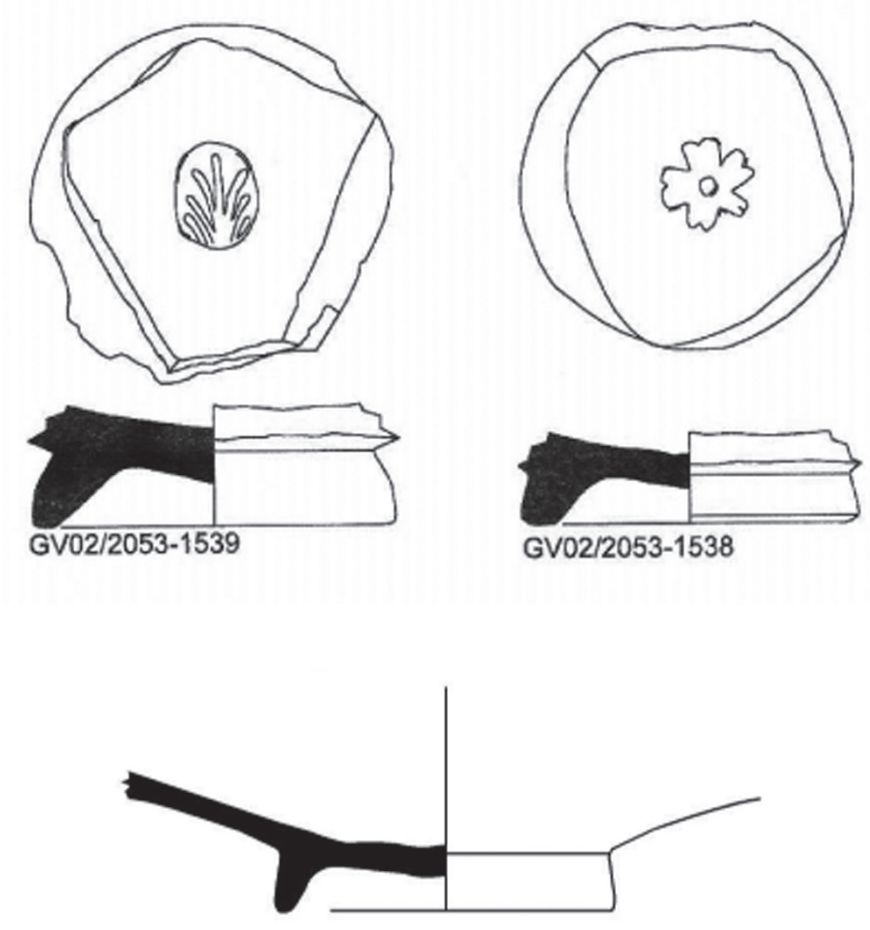

G.V.'02 2054-1589

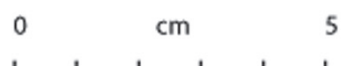

Figura 1.- Fragmentos de los talleres de Rosas procedentes del Grau Vell (Sagunto), hallados en niveles datados entre el 325 y el 250 a.C. (dib. V. Albelda). 


\section{Hemeroskopeion, EL MONTGó Y SU ENTORNO}

El macizo del Montgó (753 m.s.n.m.) en la Marina Alta (Alicante) (fig. 2) supone una referencia privilegiada para los navegantes que se aproximan al extremo oriental de la Península y cuenta con distintos yacimientos, bien en cuevas ocupadas desde el eneolítico (Cova Foradada, Cova Ampla, Cova del Montgó...), algunas con manantiales de agua, pinturas rupestres y cerámicas rituales, o bien al aire libre para la protohistoria (Tossal de Santa Llúcia, Alt de Benimaquia, La Plana Justa...) y romanización (Penya de l'Àguila...). En la cumbre, un triple lienzo construido en seco articula la cima denominada Penya de l'Àguila, que deviene un recinto con una posible cisterna en el centro, sin apenas construcciones en su interior. Las cortinas edificadas son inoperantes para la defensa por su disposición aunque, sin duda, tuvieron alguna razón de ser. El horizonte marítimo que domina el ambiente que delimitan las hace susceptibles de definir el témenos de un espacio sacro, por qué no del santuario reclamado por los textos antiguos, en apoyo de lo cual puede aducirse el sentido con que se ha interpretado un caso, no igual pero comparable, en El Coberxo Blanc de Calescoves (Alaior) (Orfila et al., 2010: 439-477, fig. 2). Aunque la Penya de l'Àguila no ha sido objeto de excavación (Schubart, 1963: 5186), ha dado en prospección materiales de los siglos II y I a.C., que en absoluto agotan su contextualización. Entre estos hallazgos Schubart señaló un fragmento ibérico decorado con las patas de un caballo, objeto poco explícito aisladamente, pero que pertenece a una pieza singular, no común. El hallazgo casual de los tres collares y un colgante de oro en 1999, también parece haber tenido lugar en esta zona.

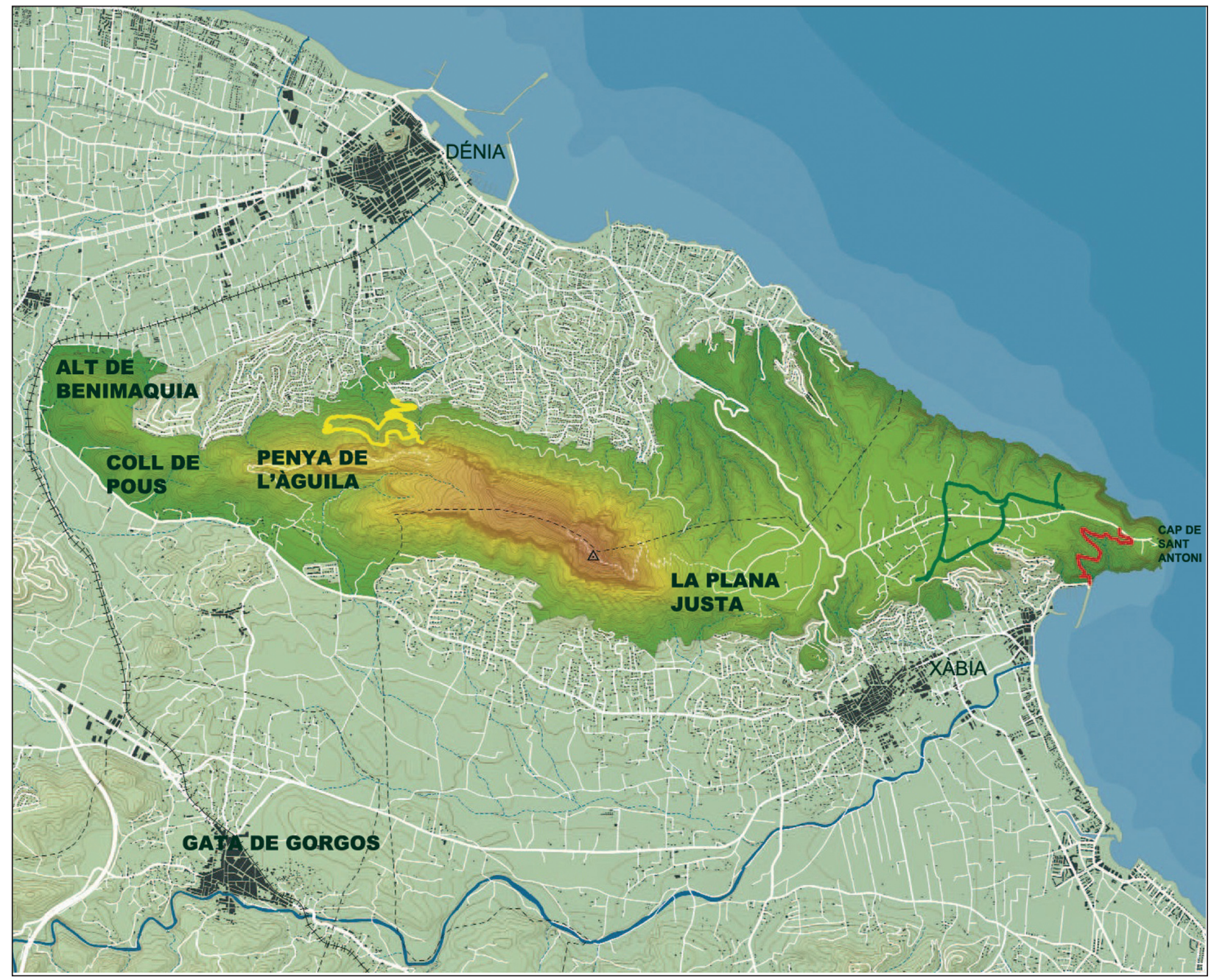

Figura 2.- La Penya de l'Àguila en la cima del Montgó (Marina Alta, Alicante) y los principales yacimientos prerromanos. 
Las citas de los autores clásicos que relacionan Dianium (Denia) con el Artemision de Hemeroskopeion -un observatorio elevado- y hacen derivar el nombre de la ciudad romana del citado un santuario foceo-masalieta (Rouillard, cit.: 299), han tenido hasta ahora insuficiente confirmación arqueológica, puesto que no se identificaban los restos existentes como aval de las fuentes escritas (Martín, 1970). No obstante, si, como al inicio de este párrafo, se abre algo más el criterio con que se interpreta el registro arqueológico dianense, aparece, además de la serie de cuevas y los recintos en la cumbre, pendientes de estudio sistemático, una inusual concentración de hallazgos de objetos de valor entre Denia y Jávea sobre la que merece la pena profundizar. ¿Por qué se repiten las ocultaciones de objetos preciados en el Montgó, Jesús Pobre, Gata, Pedreguer y Jávea? Los hallazgos de monedas y joyas ofrecen aquí a la investigación, pese a la nefasta incidencia del expolio, un panorama bastante más rico de lo habitual en la franja contestana litoral, puesto que noticias y publicaciones que se remontan al siglo XIX (Chabás, 1898: 59-64) y prosiguen hasta la actualidad ponen de manifiesto la indicada concentración de tesoros (Ripollès, 2009: 76-84). Se trata de un fenómeno que se produce de manera significativa al final del siglo IV a.C., de atenerse a la cronología que se ha dado al tesoro griego hallado casualmente en el Coll de Pous, frente al caserío de Jesús Pobre, publicado por Roque Chabás (1844-1912) (un total de 16 monedas de Emporion, Massalia, Messana, Selinunte, Leontinos, Siracusa, Corinto y un divisor de Cartago, además de algo de plata en bruto y fragmentos de medallones y cadenas de plata), datación que coincide con la del tesoro de Lluca (Llidó, 1986, con bibliografía anterior), el cual añade al panorama una connotación ibérica, pues mientras se discute si las ocultaciones básicamente de la moneda citada pueden reflejar, o no, un atesoramiento propiamente ibérico, la tipología de la diadema, en este lugar, no puede ser más que ibérica.

Visto este contexto arqueológico con mayores implicaciones, desde una perspectiva numismática, el tesoro griego del Montgó debe ser valorado en un marco más amplio que el estrictamente regional. En la vertiente mediterránea ibérica, los tesoros monetarios de esta cronolo- gía (los de Rosas, Pont de Molins, Tarragona, Morella, Orihuela, v. Villaronga, 1993) y también los hallazgos de menor entidad, como el del Puig de la Nau (Benicarló) (Oliver, Perea, 1999: 198-208), suelen tener plata sin acuñar y, siempre, piezas numismáticas emporitanas, masalietas y, algunos, de diversas ciudades griegas de Sicilia y del sur de Italia, así que, de acuerdo con Ripollès, constituyen conjuntos comparables entre sí, que no son el resultado de la circulación local, sino que han llegado formados a los lugares de ocultación, como una riqueza acumulada por gentes de mar que transitan por puertos griegos y por el corredor mediterráneo ibérico. El mapa de dispersión de estas ocultaciones jalona una ruta que se prolonga de norte a sur, que asocia la costa entre cabo de la Nao y el Segura, entendida en un sentido amplio, a Marsella y plantea la necesidad de puntos de escala náutica intermedios.

Complemento de dicha riqueza numismática son, en el caso del Montgó, el depósito de joyas de Lluca al que pertenece la diadema de Jávea y el hallazgo de otras interesantes gargantillas y colgantes de oro en La Penya de l'Àguila (Perea, 1996: 102-104; Perea, Aranegui, 2001). Alicia Perea ve en la banda-diadema una sofisticada orfebrería debida a manos griegas o magno-griegas; una pieza excepcional que es, de las de su clase (diademas del Cortijo de Évora, Mairena del Alcor, Puebla de los Infantes, todas halladas en contextos del siglo III a.C.), la que mejor combina una tipología occidental con una elaboración griega, quizá realizada en un taller peninsular (fig. 3). El prototipo, caracterizado por los extremos triangulares, aparece en el ajuar funerario de La Aliseda (Cáceres), a finales del siglo VII o inicios del VI a.C., pero las técnicas de filigrana, calado y soldadura de Jávea son tan refinadas que no pueden atribuirse más que a un orfebre griego o magno-griego del siglo IV, ya que antes de esta fecha esa manera de ir estirando el hilo de oro para conseguir la filigrana no se conocía. El dominio del oficio denota, en suma, que un artesanado especializado en producir bienes de prestigio trabajó (¿en la zona?) para las damas iberas (usuarias de este tipo de alhaja) (Aranegui, 2010a: 185-194), lo que sugiere la presencia de orfebres itinerantes para una clientela selecta y tradicional, como ocurría en otras cultura coetáneas (Botto, Oggiano, 2003: 129- 


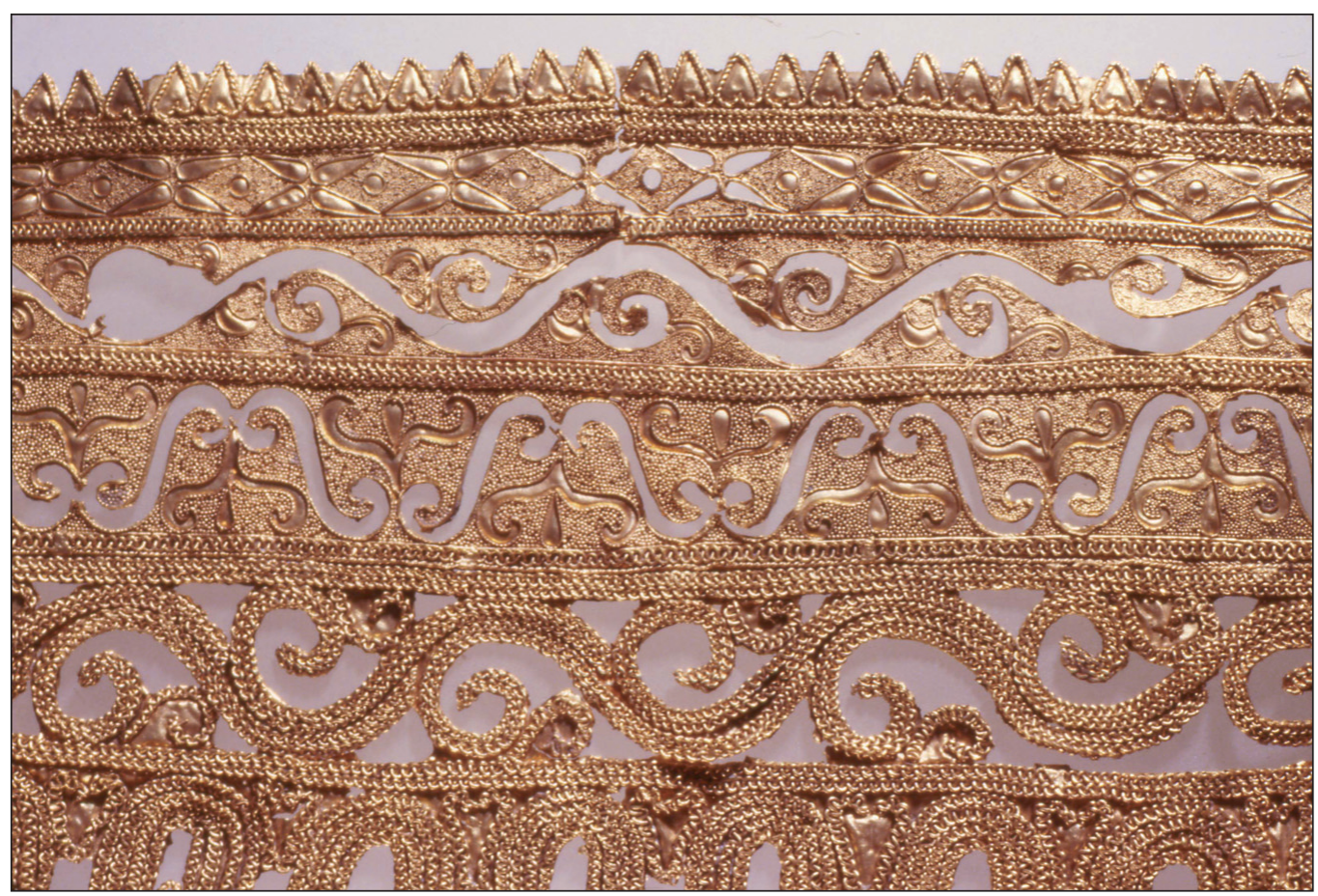

Figura 3.- La banda-diadema de Javea (Museo Arqueológico Nacional) (fot. A. Perea).

146), en las que las minorías que detentaban el prestigio de la alta sociedad tenían a su servicio a expertos artesanos, a veces extranjeros. El ajuar con instrumental de orfebre de la tumba 100 de Cabezo Lucero (Guardamar del Segura) (Perea, Armbruster, 2011: 158-171), del siglo IV, denota la apropiación por parte de las elites iberas de lo necesario para fabricar joyas.

Para el encuadre político de estos contactos greco-ibéricos, hay que tener en cuenta que, en el siglo IV a.C., no solo Ampurias se había desligado de Marsella (Santos, 2008: 49-79) sino que también Rosas desplegaba su propia política con respecto a las poblaciones autóctonas de su entorno, algunas de las cuales se clausuraron (Peralada) con posible traslado de sus habitantes a la colonia, mientras que otras alcanzaron en este momento su pleno desarrollo urbanístico y territorial, como ocurrió en El Puig de Sant Andreu (Ullastret) (Margall et al., 2002: 237250), al sur de Ampurias, dando a entender que la política griega pasaba en ese momento por reforzar los oppida ibéricos que se declaraban afines. De modo que es verosímil que la relación del sureste con el circuito de Marsella estuviera mediatizada por la participación de las jefaturas ibéricas, ya que fundaciones coloniales propiamente dichas no puede afirmarse, hasta el momento, que tuvieran lugar.
En la actualidad se conoce bastante mejor la ocupación humana ibérica de la Marina Alta (Castelló, Costa, 1992: 7-19; íd. 1999: 97-108; Grau, 2004: 61-75) y, en concreto, de la zona de Denia y Jávea (Bolufer, 1999; Bolufer, Vives Ferrándiz, 2003: 69-86; Bolufer, Sala, 2009), que en el momento en que Llobregat publicara su Contestania Ibérica (1972). La fase protohistórica colonial se materializa en el Montgó en los siglos VII-VI a.C., con los yacimientos de Benimaquía (Castelló et al., 2000: 121-136) y La Plana Justa, que se prolonga hasta el Ibérico Antiguo; el Ibérico Pleno tiene un exponente fundamental en El de Coll de Pous. Pero, sin embargo, la secuencia cronológica de Dianium sigue siendo imprecisa en lo que respecta a la etapa prerromana, por lo que resulta difícil atribuir una categoría político-administrativa a este núcleo para el momento en que los tesoros del Coll de Pous y Lluca fueron enterrados.

En efecto, la cuestión fundamental que se impone ante el estado de cosas expuesto tiene que ver con la localización de un centro habitado capaz de articular todos los hallazgos de tesoros. ¿Dónde está ese núcleo? ¿se puede situar en el Coll de Pous? ¿en Denia? ¿se conoce algún poblado en la zona destruido a finales del siglo IV? ¿qué sentido tiene la cita de Estrabón III, 4,6? (Cruz Andreotti, 2002: 153-180). La falta 
de definición respecto al oppidum central de la comarca, siendo importante, no invalida los argumentos para reconocer un santuario en el Montgó, sin duda suscitado por la topografía del monte, ritualizado ancestralmente, cuyo puerto fue conocido no solo por los navegantes del siglo IV a.C. sino también por los romanos (Cic. Verr., 1, 87,5,146), véase Sertorio, que, tiempo después, volvieron a frecuentar la misma cima en época republicana y nombraron a la ciudad principal de la zona Dianium, ciertamente con alguna lógica (Aranegui, 1996: 13-27).

El santuario con el que Denia se relaciona debió concentrar donaciones de gentes involucradas en el comercio marítimo, cuyo desarrollo afectaría tanto a la población local como a los agentes externos (Aranegui, 2005: 116-129). Las ofrendas sacras atribuibles a los comerciantes suelen ajustar su valor al del montante de las transacciones que se realizan e incluso atenerse a tarifas establecidas, muy frecuentes en los santuarios empóricos. De este modo algunos santuarios litorales: Gravisca en Etruria, Gadir en el Estrecho..., llegaron a ser inmensamente ricos, $\mathrm{y}$, consiguientemente, vulnerables en tiempos de inestabilidad. Por necesidades tácticas o políticas muchos de ellos se vieron obligados a ceder sus riquezas, o fueron directamente profanados, por causas muy diversas de entre las que la piratería no fue la menor. Ante tales amenazas, la riqueza era escondida bajo tierra, como es evidente que ocurrió en el Montgó y su entorno.

\section{La fortificación de La Picola (Santa Pola)}

En el siglo IV a.C. La Picola (Santa Pola) fue una pequeña fortaleza, elevada al borde del antiguo humedal de la desembocadura del Vinalopó y el Segura, de la que se ha excavado apenas una sexta parte (Badie et al., 2000) (fig. 4). El análisis de sus restos confirma que responde, para la fase indicada, a un proyecto constructivo unitario, conceptualmente sin precedentes ni paralelos locales, ejecutado según un trazado regulador de tradición griega, puesto en obra de manera no canónica. La muralla que rodea el espacio cuadrangular restituido (80 m de lado y unos $2960 \mathrm{~m}^{2}$

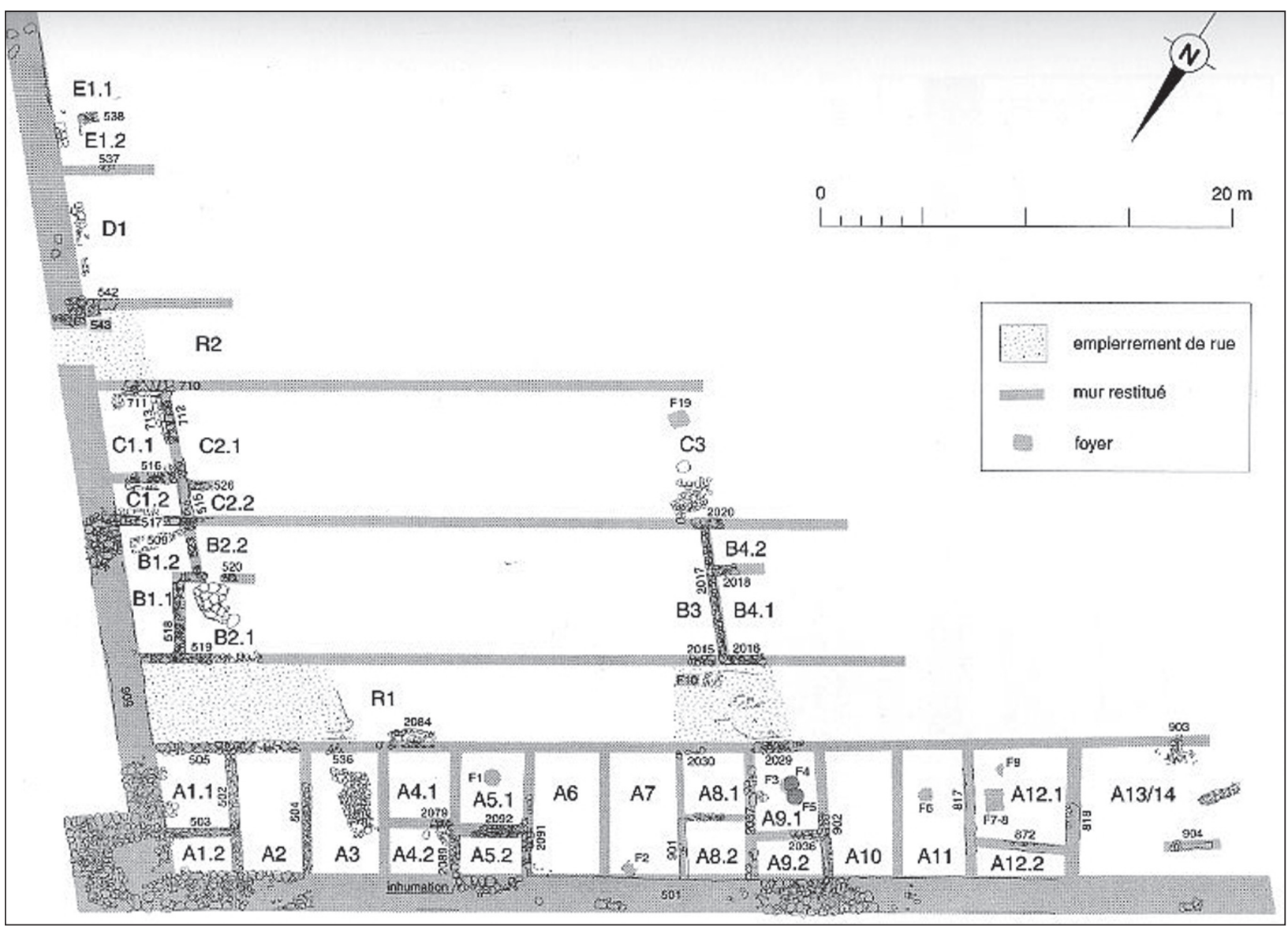

Figura 4.- La fortaleza de La Picola (Santa Pola), según Badie et al. 
intramuros), con torres en las esquinas (se conoce solo la suroeste) y precedida de fosos y antemural, hace que prevalezca su aspecto defensivo (Moratalla, 2005: 103-104), unido, sin duda, a una función portuaria y económica relacionada con el retropaís. Presenta calles rectilíneas de entre 3,5 y 3,95 m de anchura, pavimentadas y con huellas del paso de carros, provistas de algún canal de desagüe, lo que no es habitual en otros sitios próximos, aunque desde el punto de vista de los materiales cerámicos recuperados, no se ha observado un tipo de vida diferente al de los establecimientos contestanos coetáneos. Lo que más llama la atención en el medio geográfico en que se halla es su parecido arquitectónico en planta, a escala reducida y simplificada, con la colonia comercial masalieta de Olbia de Provenza (Hyères, Var) (Bats, 2004: 51-64), parecido que autoriza su consideración en el marco del proyecto griego orientado hacia el sureste peninsular.

En el sinus ilicitanus (Mela II, 93; Plin. Nat. III, 3, 20), el enclave portuario de La Picola parece necesitado de medidas de protección contundentes, no tanto frente a las gentes iberas como frente a la otra potencia marítima interesada en esta costa: los púnicos, lo que confiere al sureste un disputado valor estratégico. Y, en efecto, pese a ser una plaza fuerte, su pervivencia fue escasa (unos ochenta años) pues no superó el conflicto que acabó asimismo con diversos lugares contestanos amurallados (El Puntal de Salinas, El Puig de Alcoy, La Bastida de les Alcusses...), con un ciclo de vida igualmente corto. La inestabilidad también se hizo patente en el santuario del Montgó, a juzgar por las ocultaciones, y coincide con la destrucción de los monumentos funerarios de Cabezo Lucero (Guardamar del Segura) y su consiguiente abandono (Aranegui et al., 1993), más temprano que el de las necrópolis de $\mathrm{La}$ Albufereta, La Serreta, El Cabecico del Tesoro o El Cigarralejo.

Si desde la costa hasta el interior se reiteraron los actos de violencia, se puede deducir que algo parecido a una koiné participada por poblaciones ibéricas, quedó eliminado en el tránsito del siglo IV al III a.C. y, aunque convencionalmente esta violencia haya sido imputada a rivalidades entre oppida ibéricos, la pugna de las potencias coloniales por el control de un litoral próximo a Ibiza, bien articulado con el área del Estrecho y que da acceso a los recursos minero-metalúrgicos mur- cianos, no se puede eliminar del trasfondo del problema. Los enfrentamientos fueron dirimidos entre iberos y a la manera ibérica, pero, presumiblemente, entre iberos partidarios de Marsella e iberos partidarios de Cartago, causantes de una inestabilidad que se desconoce, en términos semejantes, al norte del Júcar y al oeste del Sistema Penibético, cuya conclusión no acarreó la eliminación de las producciones cerámicas de Rosas del comercio local, pero marcó el predominio de las ánforas púnicas de Ibiza y del Estrecho en toda la zona.

La anulación de La Picola pasa así a ser uno de los exponentes más claros del fracaso foceomasalieta en el sureste y es por su carácter efímero, unido a su reducida extensión, por lo que la deducción de Allon, Allônai, Alonis (Mela II, 6, 96; Ptol. Geog. II, 6, 14; An. Rav. 304, 16) parece no ser adecuada para este punto, sino, con más posibilidades, para Villajoyosa, más estable, ubicada un poco más al norte, donde, sin embargo, poco se sabe, de momento, sobre el siglo IV a.C. más allá del nivel de destrucción que el lugar muestra en dicha época (García León, Espinosa, 2005).

\section{LA ESCRITURA GRECO-IBÉRICA}

El pionero de la lectura de las escrituras paleohispánicas fue Manuel Gómez Moreno (18701970) (1925: 475-499). Tras reunir pacientemente un léxico entonces exhaustivo, en 1922 este investigador erudito pudo revelar que el signario prelatino más utilizado en la Península era un semisilabario de veintisiete signos básicos, más numerales, con valor simple para las vocales y para siete consonantes, pero en el que labiales, guturales y dentales se escribían con valor silábico. Para confirmar esta conclusión fue decisivo constatar que el idioma ibérico había hecho uso de tres sistemas gráficos, uno mayoritario y dos subsidiarios, estando uno de estos compuesto por grafemas jonios conocidos. De este modo, el plomo inscrito que encontrara en aquellos años Camilo Visedo Moltó (1876-1958) en La Serreta (Alcoy, Cocentaina, Penàguila) supuso un hito en su investigación, por tratarse del primer texto en lengua ibérica escrito con un alfabeto griego (MLH III, G.1.1 de Untermann), legible (pero incomprensible), hallado en un contexto del siglo III a.C. (Abad, 1983: 173-197). Fue el primero de una serie de ocho plomos y dieciséis inscripciones 
menores sobre cerámicas de importación, datados a partir del 350 a.C., que se difunden solo entre Alicante y Murcia, con alguna rara excepción, como un plomo atribuido al área saguntina. Los plomos greco-ibéricos de La Serreta (5) y Coimbra del Barranco Ancho (Jumilla) (1) contienen signos numéricos, como el de Sagunto, que, sin duda, indicaban datos precisos para quienes los escribieron y leyeron, partícipes de un sistema contable que estos documentos, como las escalas ponderales, reflejan en una zona que asiste a una involución en sus intercambios en el siglo IV. Por el contrario, el plomo de la tumba 21 del Cigarralejo (Mula), redondo e inscrito en líneas serpenteantes, tiene un texto de otras características, sin cifras, tal vez mágico.

Esta escritura (de Hoz, 2009: 31-41), circunscrita a un pequeño número de localidades y ocurrencias (fig. 5), deja constancia de la adaptación en el siglo IV a.C., aparentemente efímera, de un alfabeto externo, con probabilidad llegado aquí desde Marsella, para escribir, principalmente, albaranes en ibérico, lo que constituye un epifenómeno colonial exclusivo de las áreas valenciana y murciana. Si la conexión hubiera sido con Emporion o Rhode el signario no hubiera sido el jonio de la escritura del sureste, porque en el Ampurdán, sobre todo en esta época, el ibérico se escribía con el signario oriental, sin duda conocido en el ambiente comercial de la zona.

De Hoz (1984: 11-14) interpretó la aparición del greco-ibérico como un hecho precoz de la escritura entre los iberos, producido por la iniciativa de escribir de alguien que, hablando la lengua que llamamos ibérica, tomó prestados los signos jonios que se adaptaban mejor a dicha habla. Así concluyó que el ibero debía ser la lengua vernácula de la Contestania litoral septentrional, que pronto adquirió categoría vehicular a lo largo de la geografía de la cultura ibérica debido al comercio. Sin embargo, esta argumentación es matizable si se aceptan básicamente tres objeciones bien documentadas: primero, que las inscripciones greco-ibéricas no son las más antiguas de las que notan el ibérico, ni tienen sus mejores exponentes en la costa de Alicante, sino en La Serreta, oppidum del interior cuya fecha inicial se sitúa a comienzos del siglo IV a.C.; segundo, que en el siglo IV es probable que hubiera gentes bilinguies circulando por el territorio ibérico, alguna de las cuales podía hablar en ibero sin ser del país, recurriendo al signario jónico, que tal vez era el suyo, para escribir, con lo que el préstamo del escriba sería inverso al sugerido por de Hoz; y, por último, que, a la vista de los documentos, el grecoibérico es un fenómeno que tuvo poca trascendencia en el tiempo y en el espacio ibéricos para ser considerado el motor de su alfabetización. Aunque la cantidad no sea una razón decisiva ¿Qué son veinticuatro inscripciones frente a las casi dos mil escritas con el sistema oriental que, además, aporta ejemplos que pueden remontarse a finales del siglo V a.C.?

Concurren en el greco-ibérico, sin embargo, algunas características que conviene recordar, como son un alto porcentaje relativo de plomos (33,3\% del total de casos) y una presencia de grafitos concentrados en la cerámica ática de barniz

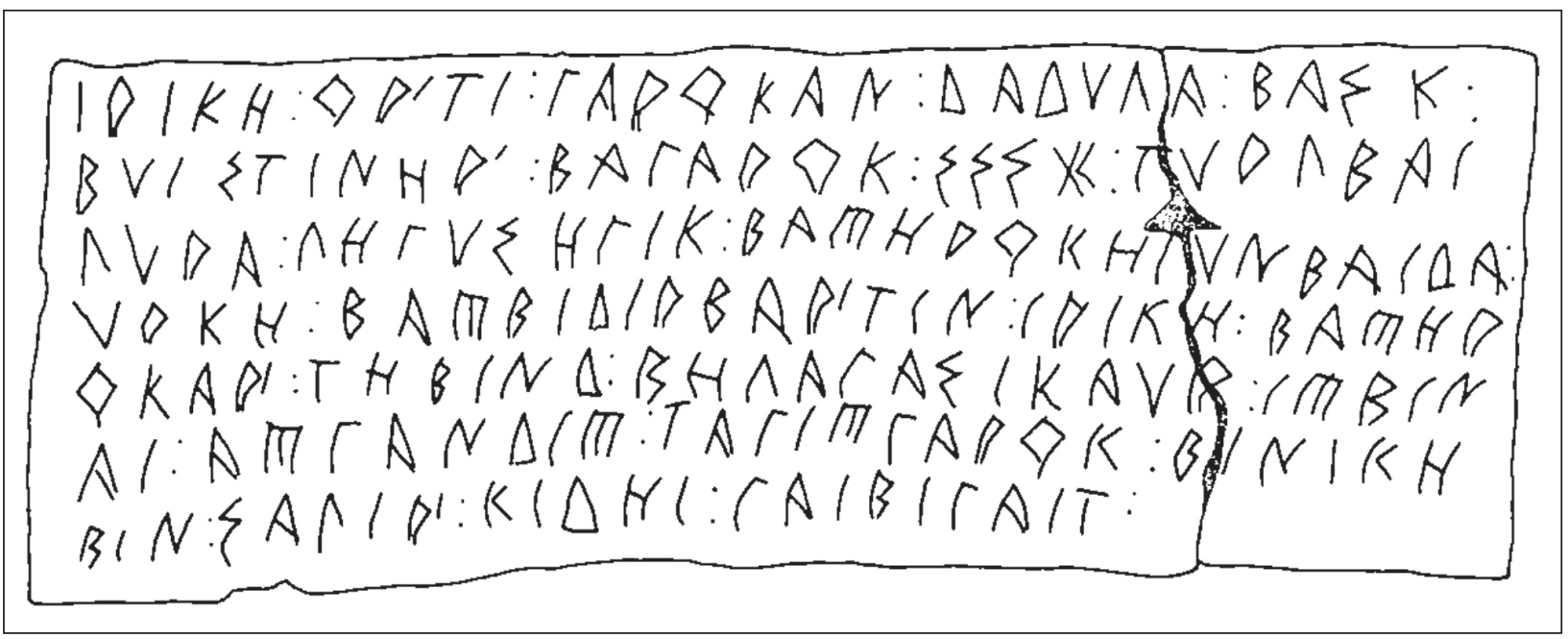

Figura 5.- Calco del plomo MLH G.1.1 de La Serreta (cortesía del Museo de Alcoy). 
negro, salvo una excepción, que supone un 6,2\% de los casos. Estos últimos proceden mayoritariamente de La Illeta dels Banyets (Campello) (Olcina et al., 2009) donde también concurre algún grafito púnico (Llobregat, 1989: 146-166) y griego, siempre en el pie externo de copas de pie bajo áticas, a las que se suma un plato de pescado. De entrada, se trata de un conjunto de letreros que denota prácticas distintas de las que se desprenden de los grafitos en ibérico oriental, grabados sobre soportes mucho más diversificados. También interesa destacar el peculiar contexto del hallazgo del lote de las excavaciones de Llobregat en Campello: en una fosa que contenía restos de comida con escamas de pescado ¿quizá de una ceremonia convivial en un ambiente plural de redistribuidores? Es probable, porque el enclave en sí, de alrededor de 2 Ha de extensión, se presenta como una instalación industrial y mercantil abierta al mar, con una fuerte impronta púnica en sus equipamientos (Aranegui, 2010b: 689-704).

Sin ánimo de zanjar una cuestión tan compleja y especializada como es la de la escritura, parece oportuno insistir en que un escriba que domina los signos jonio-focenses en el siglo IV a.C. debía pertenecer al ambiente cultural masalieta. Que el uso por parte del mismo de la lengua que llamamos ibérico muestra la intención de integrar a las poblaciones locales en el objetivo que persigue, hecho compartido con las demás actuaciones aquí consideradas. Y que el greco-ibérico desaparece igual que lo hacen los puntos estratégicos del ámbito alicantino y murciano que, en el siglo III, recibirán de manera muy acusada una influencia púnica.

\section{EN CONCLUSIÓN}

Por lo tanto, los hechos destacados en este trabajo pueden proponerse como resultado de una expansión que de lo comercial pasa a lo cultural (Aranegui, 1994: 115-138), ampliando entre las minorías ibéricas el uso de la escritura e introduciéndolas en la circulación monetaria. Y, si esta interpretación se considera adecuada, la violencia que le pone fin habría que argumentarla como preludio del clima de hostilidades que llegará a sus últimas consecuencias en la demarcación territorial que establece el tratado romano-cartaginés llamado del Ebro (226 a.C.) (Polyb. III, 24, 2-4; Apiano II, 7), que supone una ampliación considerable del área de libre navegación para los púnicos, con anterioridad circunscrita hasta Mastia (Díaz Tejera, 1996).

No hace falta localizar dónde se ubicaban los comerciantes masalietas, puesto que sigue sin aparecer en la región un centro que pueda denominarse urbano y griego. Sin embargo se van multiplicando las evidencias de barrios mixtos, productivos, construidos extramuros, en Rosas, en Ampurias, en La Illa d'en Reixac del Puig de Sant Andreu (Ullastret) y, también, en El Tossal de les Basses junto a La Albufereta y en el sector alfarero de La Illeta dels Banyets de Campello. Se descubre así un modelo de hábitat que alberga grupos artesanales, directamente relacionado con un tráfico marítimo en principio no excluyente, complementario de la cadena de instalaciones litorales que vehicularon el floreciente comercio que transitaba por las costas ibéricas.

La perspectiva del siglo XXI, en definitiva, saca la cita de Estrabón de unas explicaciones negativas, accidentales o banales, en pro de su inserción histórica, que anima a documentar mejor la arqueología del siglo IV a.C. en nuestras costas.

\section{Bibliografía}

ARANEGUI, C. (1994): "Iberica sacra loca. Entre el cabo de la Nao, Cartagena y El Cerro de los Santos", REIb 1: 115-138.

ARANEGUI, C. (1996): "Los orígenes de la ciudad de Denia en Roc Chabás", Saitabi 46, 13-27.

ARANEGUI, C. (2004): Sagunto. Oppidum, emporio y municipio romano, Barcelona.

ARANEGUI, C. (2005): “Arqueología de la tradición portuaria valenciana”, K. de Barañano, com., $L a$ mar de arte/Art Galore, Valencia, 116-129.

ARANEGUI, C. (2010a): "El lenguaje del prestigio: a propósito de la Dama de Baza", T. Chapa, I. Izquierdo, coords., La Dama de Baza. Un viaje femenino al Más Allá, Madrid, 185-194.

ARANEGUI, C. (2010b): "Ocupación económica, ritual y estratégica del litoral valenciano", Mainake 32, 2: 689-704.

ARANEGUI, C., JODIN, A., LLOBREGAT, E., ROUILLARD, P., UROZ, J. (1993): La nécropole ibérique de Cabezo Lucero (Guardamar del Segura, Alicante), CCV 41, Madrid. 
BADIE, A., GAILLEDRAT, E, MORET, P., ROUILLARD, P., SÁNCHEZ, M'J., SILLIÈRES, P. (2000): Le site antique de La Picola à Santa Pola (Alicante), Casa de Velázquez, Madrid. Paris.

BATS, M. (2004): "Les colonies massaliètes de Gaule méridionale: sources et modèles d'un urbanisme militare aux IVe-IIIe siècles avant J.-C.", S. Augusta-Boularot, X. Lafon, eds., Dès Ibères aux Vénètes, Roma, 51-64.

BENDALA, M. (1976): La necrópolis romana de Carmona (Sevilla), Sevilla.

BENDALA, M. (2001): "La Carmona bárquida", Carmona romana, Sevilla, 37-52

BOLUFER, J. (1999): "L'arqueologia subacuàtica a Xàbia", Revista de festes patronals.

BOLUFER, J., VIVES-FERRÁNDIZ, J. (2003): “La Plana Justa (Xàbia, Alicante): un nuevo yacimiento con materiales fenicios y del Ibérico Antiguo", Saguntum 35, 69-86.,

BOTTO, M., OGGIANO, I. (2003): "L'Artigianato", J.Á. Zamora, ed., El hombre fenicio. Estudios y materiales, Madrid, 129-146.

CASTELlÓ, J., COSTA, P. (1992): "El jaciment ibèric del Coll de Pous", Aguaits 8, 7-19.

CASTElló, J., COSTA, P. (1999): "La Cultura Ibérica. Poblamiento y hábitat", Historia de la Marina Alta, Alicante, 97-108.

CHABÁS, R. (1891): "El tesoro griego del Montgó", El Archivo 5, 59-67.

DÍAZ TEJERA, A. (1996): El Tratado del Ebro y el origen de la Segunda Guerra Púnica, Universidad de Sevilla, Sevilla.

CRUZ ANDREOTTI, G. (2002): “Iberia e Iberos en las fuentes histórico-geográficas griegas: una propuesta de análisis", Colonizaciones e Indígenas en la Península Ibérica, Mainake 24, Málaga: 153-180.

EBEL, CH. (1976): Transsalpine Gaul. The emergence of a Roman Province, Studies of the Dutch Archaeological and historical Society, Leiden.

GARCÍA CANO, J.M. (2005): "El comercio en base a la necrópolis", V. Page, dir., Museo de arte ibérico El Cigarralejo de Mula. La colección permanente, Murcia: 77-86.

GARCÍA LEÓN, J.M., ESPINOSA, A., eds. (2005): Ias. Jornadas sobre la actualidad del patrimonio arqueológico de la Marina Baixa, Universidad Miguel Hernández, campus de Altea, Alicante.
GÓMEZ MORENO, M. (1925): "Sobre los iberos y su lengua", Homenaje a Menéndez Pidal III, Madrid, 475-499.

GRAU, I. (2004): “La construcción del paisaje ibérico. Aproximación al territorio protohistórico de la Marina Alta", Saguntum 36: 61-75.

De HOZ, J. (1984): "Los grafitos de El Cigarralejo y los signos mercantiles griegos en Hispania", BAEAA 19: 11-14.

De HOZ (2009): "La escritura greco-ibérica", M. Olcina, J.J. Ramón, eds., Huellas griegas en la Contestania ibérica, Alicante: 31-41.

LLIDÓ, R. (1986): El tesoro ibérico de Jávea, Alicante.

LLOBREGAT, E.A. (1972): Contestania Ibérica, Alicante.

LLOBREGAT, E.A. (1989): “Los 'grafitti' en escritura grecoibérica y púnica de la Illeta dels Banyets. El Campello, Alicante", Homenaje a D. Domingo Fletcher, APL 19, 3: 146-166.

MALUQUER DE MOTES, J. (1965): “Rhode, Rosas, la ciudad más antigua de Cataluña. (Un capítulo inédito de la historia de Cataluña)", Revista de Gerona 31: 17-22.

MARGALL, J., CASAS, S., CODINA, F., DE PRADO, G., UNTERMAN, J. (2002): "Noves aportacions al coneiximent de l'ampliació nord de l'oppidum del Puig de Sant Andreu (Ullastret, Baix Empordà)", Cypsela 14, 237-250.

MARTÍN ÁVILA, G. 1970: Dianium. Arqueología romana de Denia, Valencia.

OLCINA, M.H., MARTÍNEZ CARMONA, A., SALA, F. (2009): La Illeta dels Banyets (El Campello, Alicante). Épocas ibérica y romana, MARQ Serie Mayor 4, Alicante.

OLIVER, A., PEREA, A. (1999): “El depósito ritual del Puig de la Nau (Benicarló, Castellón)", QPAC 20, 196-208.

ORFILA, M., BARATTA, G., MAYER, M. (2010): "Los santuarios de Calescoves (Alaior, Menorca): Coberxo Blanc y Cova dels Jurats o de L'Esglesia. Informe preliminar", Prehistoria 20, 439-477.

PEREA, A. (1996): "La orfebrería peninsular en el marco del arcaísmo mediterráneo: dos perspectivas", R. Olmos, P. Rouillard, eds., Formas arcaicas y arte ibérico, Madrid, 95-110.

PEREA, A., ARANEGUI, C. (2000): Argantonio: Rey de Tartessos, Alicante. 
PEREA, A., ARMBRUSTER, B. (2011): “Tomb 100 at Cabezo Lucero: new light on goldworking in fourth-century BC Iberia", Antiquity 85: 158-171.

PÉREZ BALLESTER, J. (1994): "La cuestión de las importaciones itálicas al sur del Ebro anteriores a las guerras púnicas. A propósito de un vaso de Gnathia procedente de Ibiza", Saguntum 27, 189-205.

PUIG, A.M; MARTÍN, Ma A., coords. (2006): La colònia grega de Rhode (Roses, Alt Empordà), Girona.

PUIG, A.M. (2010): "Rhodé (c. 375-195 av. J.-C.)", H. Tréziny, ed., Grecs et indigènes de la Catalogne à la Mer Noire, París, 79-88.

RIPOLLÈS, P.P. (2009): "El dinero en la Contestania durante los siglos V-III a.C.”, M. Olcina, J.J. Ramón, eds., Huellas griegas en la Contestania Ibérica, MARQ, Alicante, 62-74.

ROLDÁN, L., BENDALA, M., BLÁNQUEZ, J., MARTÍNEZ LILLO, S. (2006): Estudio histórico-arqueológico de la ciudad de Carteia (San Roque, Cádiz), 1994-1999, Madrid.
ROUILLARD, P. (1991): Les Grecs et la péninsule Ibérique du VIIIe an IVe Siècle avant. Jésus Christ, Centre Pierre Paris - Casa de Velázquez, Paris.

SANTOS, M. (2008): “L'arqueologia grega a Empúries. Un discurs en construcción”, 100 anys d'excavacions arqueològiques a Empúries. Hipòtesis i certeses, Annals de l'Institut d'Estudis Empordanesos 39, Figueres: 49-79.

SCHUBART, H. (1963): "Untersuchungen an den Iberischen Befestigungen des Montgó bei Denia (Prov. Alicante)", $M D A(M)$ 4, 51-85.

UNTERMANN, J. (1990): Monumenta Linguarum Hispanicarum, III. Die iberischen Inschriften aus Spanien, Wiesbaden.

VILLARONGA, L. (1993): Tresors monetaris de la Península Ibèrica anteriors a August, Barcelona 
